\title{
ESTERCO BOVINO E POTÁSSIO NA COMPOSIÇÃO MINERAL DE PLANTAS DE NONI
}

\author{
CATTLE MANURE AND POTASSIUM IN THE MINERAL COMPOSITION OF NONI PLANTS
}

\author{
João José Mendes Silva ${ }^{1}$ Lourival Ferreira Cavalcante ${ }^{2}$ José Adeilson Medeiros Nascimento ${ }^{3}$ \\ Belisia Lucia Moreira Toscano Diniz ${ }^{4}$ Antônio Gustavo Luna Souto ${ }^{5}$
}

\begin{abstract}
RESUMO
O noni tem sido utilizado desde a antiguidade para o tratamento de uma série de doenças tais como, alergia, artrite, asma, câncer, depressão, diabetes, má-digestão, hipertensão e insônia e utilizado como suplemento alimentar. Apesar dessas propriedades e da sua adaptabilidade intercontinental, as informações a respeito das exigências nutricionais e do manejo agronômico da cultura ainda são pouco frequentes na literatura internacional e nacional. Nesse sentido, o trabalho teve como objetivo avaliar os efeitos do esterco bovino e da adubação potássica no estado nutricional de plantas de noni. O experimento foi desenvolvido no período de julho de 2009 a julho de 2010, na Chácara Pau Brasil, São Luís - MA. O delineamento experimental foi em blocos casualizados com três repetições e duas plantas por parcela. Os tratamentos foram distribuídos em arranjo fatorial $2 \times 4$, referente à ausência e presença de adubação potássica $\left(130 \mathrm{~kg} \mathrm{ha}^{-1}\right.$ de $\left.\mathrm{K}_{2} \mathrm{O}\right)$ no solo com quatro doses de esterco bovino $\left(0,1,7,6,6\right.$ e 11,6 $\left.\mathrm{kg}_{\text {planta }}{ }^{-1}\right)$ fornecidas em cobertura na área de projeção da copa das plantas. Pelos resultados, exceto sobre cálcio e magnésio, a interação matéria orgânica e potássio contribuiu para aumentos dos teores foliares dos demais macro e micronutrientes nas plantas de noni. O estabelecimento de faixas de interpretação com teores de nutrientes adequados para noni se faz necessário para auxiliar as discussões de futuros estudos de adubação e nutrição da cultura.
\end{abstract}

Palavras-chave: Morinda citrifolia; adubação orgânica; adubação mineral.

\begin{abstract}
Noni fruit has been used since antiquity for treatment of many diseases such as allergy, arthritis, asthma, cancer, depression, diabetes, digestion, hypertension, and insomnia and is used as food supplement. Although these properties and its intercontinental adaptability, information about nutrient exigency and crop management is still little frequent in international and national literature. In this direction an experiment was carried out, during the period of July/2009 to July/2010, in São Luis, Maranhão state, Brazil, in order to evaluate effects of manure and potassium fertilization of the soil on mineral composition in leaves dry matter of noni plants. The treatments were arranged in randomized blocks $2 \times 4$ referring to absence and presence potassium fertilization $\left(130 \mathrm{~kg} \mathrm{ha}^{-1} \mathrm{~K}_{2} \mathrm{O}\right)$ in soil with bovine manure levels $\left(0,1.7,6.6\right.$ e $\left.11.6 \mathrm{~kg} \mathrm{plant}^{-1}\right)$
\end{abstract}

1 Engenheiro Agrônomo, Dr., Professor da Unidade de Estudos de Agronomia, Universidade Estadual do Maranhão, Cidade Universitária Paulo VI, Bairro São Cristovão, Caixa-postal 09, CEP 65000-000, São Luís (MA), Brasil. jji_mendes@hotmail.com

2 Engenheiro Agrônomo, Dr., Professor do Programade Pós- Graduação em Agronomia, Centro de Ciências Agrárias, Univiersidade Federal da Paraíba, Campus II, Cidade Univiersitária, Rodovia BR 079, Km 12, CEP 58397-000, Areia (PB), Brasil. lofeca@cca.ufpb.br

3 Engenheiro Agrônomo, Professor do Instituto Federal de Educação, Ciência e Tecnologia do Ceará, Campus Tianguá, Rodovia CE 187, CEP 62320-000, Tianguá (CE), Brasil. adeilson.nascimento@ifce.edu.br

4 Engenheira Agrônoma, Dra., Professora do Centro de Ciências Humanas Sociais e Agrárias, Universidade Federal da Paraíba, Campus III, Cidade universitária, CEP 58220-000, Bananeiras (PB), Brasil. belisia.diniz@gmail.com

5 Engenheiro Agrônomo, Doutorando do Programa de Pós-Graduação em Fitotecnia, Departamento de Fitotecnia, Universidade Federal de Viçosa, Cidade Universitária, CEP 36570-000, Viçosa (MG), Brasil. gusluso@hotmail.com

Recebido para publicação em 22/05/2012 e aceito em 23/05/2013

Ci. Fl., v. 24, n. 4, out.-dez., 2014 
applied in the area of plant projection . From the results, except in calcium and magnesium, the interaction bovine manure $\mathrm{x} \mathrm{K}_{2} \mathrm{O}$ proportioned increment on the content of other macro and micronutrients in dry matter leaf of noni plants. The establishment of levels interpreting nutrient content suitable for noni is needed to assist the discussions of future studies of fertilization and crop nutrition.

Keywords: Morinda citrifolia; organic fertilization; mineral fertilization.

\section{INTRODUÇÃO}

O noni (Morinda citrifolia L.) pertence à família Rubiaceae, cresce extensivamente entre as ilhas do Pacífico e é uma das mais significantes fontes da medicina tradicional dessas comunidades. Os povos polinésios já a usavam como planta medicinal há mais de 2000 anos e ainda hoje é utilizada na medicina tradicional para diversas enfermidades tais como: alergia, artrite, asma, câncer, depressão, diabetes, má-digestão, hipertensão, insônia, aumento da capacidade física (BASAR et al., 2010).

A planta apresenta-se como rústica, cresce nos mais diversos tipos de solos e sobrevive em habitats adversos, como em terrenos rochosos, arenosos, costeiros e vulcânicos. Há também afirmações na literatura que é tolerante à salinidade, sobrevive às inundações periódicas das áreas pelos oceanos e até se beneficia da absorção dos minerais contidos na água do mar. Associado a essas vantagens, o noni se desenvolve e produz em áreas com precipitação média anual variando entre 250 e $4000 \mathrm{~mm}$ situadas em altitude de até $800 \mathrm{~m}$ (NELSON, 2005).

O Brasil, apesar de não ter tradição no cultivo do noni, possui potencial edafoclimático para o estabelecimento dessa cultura. No estado do Maranhão, Brasil, a espécie Morinda citrifolia foi introduzida e tem se desenvolvido e produzido adequadamente. Nesse sentido, Mendes et al. (2011) apresentam dados da avaliação da fertilidade do solo, da composição foliar em macro, micronutrientes e sódio do terço superior, médio e do terço final das plantas e dos frutos recém-formados, frutos pequenos, médios, próximos à maturação e frutos maduros, de um pomar com dois anos de idade, no município de São Luis.

Apesar da adaptação da cultura às condições edafoclimáticas do Nordeste brasileiro, assim como para qualquer outra cultura, o noni cultivado com vistas à exploração comercial deve apresentar comportamento positivo em solos equilibrados em nutrientes e matéria orgânica. No entanto, informações sobre as exigências do noni em adubação são limitadas, principalmente no Brasil. Nesse contexto, considerando a importância econômica do noni e que a cultura está em expansão, estudos sobre adubação e estratégias para aprimorar as técnicas de rendimento e reduzir os custos de produção devem ser adotados.

Devido à carência de informações sobre o manejo dessa cultura no Brasil, os dados preliminares a respeito de fertilidade do solo e adequação nutricional consideram as informações disponíveis para o café (Cofea arábica) que é uma planta da mesma família e apresenta porte e hábito de crescimento semelhante. No entanto, o noni apresenta particularidades em relação à cultura do café, como por exemplo, o formato do fruto, a floração e frutificação, o que, possivelmente, se reflete em exigência e composição nutricional diferenciada em relação ao cafeeiro. Isso indica que estudos específicos devem ser realizados visando à disponibilização de informações para potencializar o rendimento produtivo e a qualidade dos frutos.

O trabalho teve por objetivo avaliar a composição em macro e micronutrientes na matéria seca foliar de plantas de noni em solo fertilizado com esterco bovino e adubação mineral com potássio.

\section{MATERIAL E MÉTODO}

O trabalho foi desenvolvido no período compreendido entre 22 de julho de 2009 a 30 de julho de 2010, na Chácara Pau-Brasil, situada ao Sul de São Luís, Maranhão, Brasil. O local do experimento é demarcado pelas coordenadas geográficas $2^{\circ} 30^{\prime} \mathrm{S}, 44^{\circ} 18^{\prime} \mathrm{W}$ e a uma altitude de 48 m. O clima da região, segundo Köppen, é do tipo Aw', equatorial quente e úmido, com duas estações definidas: uma estação chuvosa, que se estende de janeiro a junho, e uma estação de estiagem, com deficit hídrico de julho a dezembro.

Nas precipitações pluviais da região ocorrem variações de 1700 a $2300 \mathrm{~mm}$ anuais. A temperatura média local situa-se em torno de $26^{\circ} \mathrm{C}$, as máximas variam de 28 a $37^{\circ} \mathrm{C}$ e as mínimas entre 20 e $23^{\circ} \mathrm{C}$ (NUGEO, 2002). O solo do local do experimento foi classificado como Argissolo Vermelho Amarelo 
TABELA 1: Caracterização química e física do solo à profundidade de $0-20 \mathrm{~cm}$.

TABLE 1: Chemical and physical soil $(0-20 \mathrm{~cm})$ characterization.

\begin{tabular}{|c|c|c|c|}
\hline Atributos químicos & & Atributos físicos & \\
\hline $\mathrm{pH} \mathrm{H}_{2} \mathrm{O}(1: 2,5)$ & 5,87 & Areia grossa $\left(\mathrm{g} \mathrm{kg}^{-1}\right)$ & 400 \\
\hline $\mathrm{P}\left(\mathrm{mg} \mathrm{dm}^{-3}\right)$ & 34,79 & Areia fina $\left(\mathrm{g} \mathrm{kg}^{-1}\right)$ & 428 \\
\hline $\mathrm{K}^{+}\left(\mathrm{mg} \mathrm{dm}^{-3}\right)$ & 34,97 & Silte $\left(\mathrm{g} \mathrm{kg}^{-1}\right)$ & 89 \\
\hline $\mathrm{Na}^{+}\left(\mathrm{cmol}_{\mathrm{c}} \mathrm{dm}^{-3}\right)$ & 0,08 & Argila $\left(\mathrm{g} \mathrm{kg}^{-1}\right)$ & 83 \\
\hline $\mathrm{H}^{+}+\mathrm{Al}^{3+}\left(\mathrm{cmol}_{\mathrm{c}} \mathrm{dm}^{-3}\right)$ & 4,23 & Argila dispersa $\left(\mathrm{g} \mathrm{kg}^{-1}\right)$ & 21 \\
\hline $\mathrm{Al}^{3+}\left(\mathrm{cmol}_{\mathrm{c}} \mathrm{dm}^{-3}\right)$ & 0,00 & Grau de floculação (\%) & 75,1 \\
\hline $\mathrm{Ca}^{2+}\left(\mathrm{cmol}_{\mathrm{c}} \mathrm{dm}^{-3}\right)$ & 1,70 & Índice de dispersão (\%) & 24,9 \\
\hline $\mathrm{Mg}^{2+}\left(\mathrm{cmol}_{\mathrm{c}} \mathrm{dm}^{-3}\right)$ & 0,33 & Densidade aparente $\left(\mathrm{g} \mathrm{cm}^{-3}\right)$ & 1,36 \\
\hline $\mathrm{SB}\left(\mathrm{cmol}_{\mathrm{c}} \mathrm{dm}^{-3}\right)$ & 2,20 & Densidade real $\left(\mathrm{g} \mathrm{cm}^{-3}\right)$ & 2,66 \\
\hline $\mathrm{CTC}\left(\mathrm{cmol}_{\mathrm{c}} \mathrm{dm}^{-3}\right)$ & 6,43 & Porosidade total $\left(\mathrm{m}^{3} \mathrm{~m}^{-3}\right)$ & 0,48 \\
\hline $\mathrm{V}(\%)$ & 34,21 & Umidade a - 0,033MPa (\%) & 9,12 \\
\hline $\mathrm{MO}\left(\mathrm{g} \mathrm{kg}^{-1}\right)$ & 9,85 & Umidade a - 1,500 MPa (\%) & 4,56 \\
\hline Boro $\left(\mathrm{mg} \mathrm{dm}^{-3}\right)$ & Traços & Água disponível $\left(\mathrm{g} \mathrm{g}^{-1}\right)$ & 4,56 \\
\hline Ferro $\left(\mathrm{mg} \mathrm{dm}^{-3}\right)$ & 38,03 & Classificação textural: & $\begin{array}{c}\text { F.- arenosa } \\
\text { Arenoso }\end{array}$ \\
\hline Manganês (mg dm ${ }^{-3}$ ) & 6,14 & & \\
\hline Zinco $\left(\mathrm{mg} \mathrm{dm} \mathrm{m}^{-3}\right)$ & 2,85 & & \\
\hline
\end{tabular}

distrófico latossólico, de textura franco-arenosa. Antes do início do experimento, amostras de solo foram coletadas na profundidade de $0-20 \mathrm{~cm}$, para caracterização física e química (Tabela 1) de acordo com a metodologia descrita por Embrapa (1997).

O delineamento experimental foi em blocos casualizados com três repetições e duas plantas por parcela. Os tratamentos foram distribuídos em arranjo fatorial $2 \times 4$, referente à ausência e presença de adubação potássica $\left(130 \mathrm{~kg} \mathrm{ha}^{-1}\right.$ de $\mathrm{K}_{2} \mathrm{O}$ ) no solo com quatro doses de esterco bovino $\left(0,1,7,6,6\right.$ e $11,6 \mathrm{~kg}$ planta $\left.^{-1}\right)$ de modo a elevar o teor de matéria orgânica do solo $(0,985 \%)$ para 1,5 ; 3,0 e $4,5 \%$, respectivamente. O esterco foi obtido de curral de gado leiteiro em regime semiconfinado, em que os animais permaneciam no campo durante toda a manhã e o restante do tempo no estábulo, alimentados com capim verde passado em máquina trituradora.

Por ser fermentado e armazenado à sombra, no momento da aplicação, o insumo orgânico estava comumidadede $6 \%$. Essevalordeágua foiadicionado a cada respectiva dose calculada com base na massa de solo da camada de $20 \mathrm{~cm}$ com densidade de 1,36 $\mathrm{g} \mathrm{cm}^{-3}$ (Tabela 1), na faixa compreendida de 40 a 100 cm do caule, correspondente a uma circunferência com raio de $60 \mathrm{~cm}$. Ao considerar a distribuição superficial das raízes de noni, a aplicação do esterco foi realizada na superfície do solo referente a uma faixa circunferencial referente ao raio de $60 \mathrm{~cm}$ na qual foram feitos os cálculos. Para o cálculo da quantidade de esterco a ser fornecida por planta referente a cada dose para elevar os teores do solo às percentagens supracitadas utilizou-se a expressão:

$$
\mathrm{D}_{\mathrm{E}}=\left[\left(\mathrm{Q}_{\mathrm{MOA}}-\mathrm{Q}_{\mathrm{MOE}}\right) \times \mathrm{Ms} \times \mathrm{U}\right] / 1.000
$$

Em que: $\mathrm{D}_{\mathrm{E}}=$ dose de esterco a ser aplicada por planta $\left(\mathrm{kg}\right.$ planta $\left.^{-1}\right) ; \mathrm{Q}_{\mathrm{MOA}}=$ Dosagem de matéria orgânica a ser alcançada no solo $\left(\mathrm{g} \mathrm{kg}^{-1}\right)$; $\mathrm{Q}_{\mathrm{MOE}}=$ Dosagem de matéria orgânica existenteno solo $\left(\mathrm{g} \mathrm{kg}^{-1}\right) ; \mathrm{Ms}=$ Massa da camada de solo $(\mathrm{kg})$.

$$
\text { Umidade }(\mathrm{U})=1,06
$$

equação: 


$$
\mathrm{Ms}=\pi \mathrm{R}^{2} \times \mathrm{Z} \times \mathrm{ds}
$$

Em que: $\mathrm{R}=0,6 \mathrm{~m} ; \mathrm{Z}=$ profundidade do solo $(\mathrm{m}) ; \mathrm{ds}=$ densidade do solo $\left(\mathrm{kg} \mathrm{m}^{-3}\right)$.

Uma amostra composta oriunda de cinco amostras simples do esterco bovino utilizado foi coletada para caracterização quanto aos teores de macronutrientes, micronutrientes, alumínio $\mathrm{e}^{+}$ $+\mathrm{Al}^{3+}$, pela metodologia sugerida por Embrapa (2011), cujos resultados estão na Tabela 2 . O esterco foi fornecido às plantas no início do período da estiagem, em agosto de 2009 e no início do período das chuvas em janeiro de 2010.

As plantas, no início do experimento, estavam com dois anos de idade, altura média de 1,6 m e implantadas no espaçamento de $4 \mathrm{~m} \times 4$ m (625 plantas ha $\left.{ }^{-1}\right)$, de acordo com recomendação de Macpherson et al. (2007). Antes da instalação do experimento, foi realizada uma poda de limpeza e arejamento com a retirada de parte dos ramos velhos e malformados.

As adubações fosfatadas e nitrogenadas foram comuns a todas as plantas, esta situação não constitui fonte de variação. $\mathrm{A}$ adubação fosfatada constou de $37,5 \mathrm{~kg} \mathrm{ha}^{-1}$ de $\mathrm{P}_{2} \mathrm{O}_{5}$ oriundo do superfosfato simples $\left(18 \%\right.$ de $\left.\mathrm{P}_{2} \mathrm{O}_{5}\right)$, em duas aplicações, metade no início de agosto de 2009 e a outra metade no início de janeiro de 2010.

As adubações nitrogenada com $75 \mathrm{~kg} \mathrm{ha}^{-1} \mathrm{ano}^{-1} \mathrm{de} \mathrm{N}$, na forma de ureia $(44 \% \mathrm{de}$ $\mathrm{N}$ ), e potássica com130 $\mathrm{kg} \mathrm{ha}^{-1} \mathrm{ano}^{-1}$ de $\mathrm{K}_{2} \mathrm{O}$, via cloreto de potássio $\left(57 \%\right.$ de $\left.\mathrm{K}_{2} \mathrm{O}\right)$, foram feitas simultaneamente em três aplicações iguais de $25 \mathrm{~kg}$ $\mathrm{ha}^{-1}$ de $\mathrm{N}$ e 43,33 kg ha-1 $\mathrm{K}_{2} \mathrm{O}$ nos tratamentos com potássio da seguinte forma: a primeira aplicação foi fornecida juntamente com a primeira adubação fosfatada, em agosto de 2009, e as duas outras a cada 120 dias após a primeira.
A irrigação durante a estiagem foi realizada pelo método de microaspersão, usando um microaspersor por planta com raio de alcance de 2,8 m, trabalhando na pressão de serviço de 2,2 MPa, vazão de $72 \mathrm{~L} \mathrm{~h}^{-1}$ e turno de rega a cada 48 horas. A lâmina de água aplicada foi calculada com base na evaporação média semanal de tanque classe "A", obtida pela evaporação de referência - $\mathrm{ET}_{0}$, multiplicando-se a leitura do tanque pelo fator 0,75 (BERNARDO et al., 2006).

O controle das plantas espontâneas foi realizado manualmente na área de projeção da copa das plantas e entre as linhas de plantio com roçadeira rotativa. Apesar de ter havido ocorrência de doenças bacterianas em alguns frutos na estação seca, não foi feito nenhum controle fitossanitário por ter sido de baixa incidência. No início da estação chuvosa, o problema fitopatogênico desapareceu.

Em abril de 2010, quando as plantas estavam com 33 meses, foram obtidas amostras compostas do terceiro e quarto pares de folhas do terço mediano das plantas, contados a partir do ápice de cada ramo selecionado, conforme metodologia utilizada para a coleta de amostras de folhas de café recomendada por Malavolta et al. (1997), num total de 16 folhas por planta. Por não existir informações a respeito da folha-diagnóstico do noni foi utilizada a metodologia adotada para o café que é uma Rubiaceae e, portanto, da mesma família.

Após o material ser seco em estufa, com circulação de ar, a $60^{\circ} \mathrm{C}$ durante 72 horas, e triturado em moinho tipo Willye TE - 650, foram determinados, na matéria seca das folhas, os teores de macro e micronutrientes, empregando os procedimentos metodológicos recomendados por Embrapa (1997).

Os dados obtidos foram submetidos à análise de variância. As médias referentes à adubação

TABELA 2: Caracterização química do esterco bovino utilizado para a adubação.

TABLE 2: Chemical characterization of the cattle manure used for fertilization.

\begin{tabular}{|c|c|c|c|c|c|c|c|c|c|}
\hline \multicolumn{10}{|c|}{ Fertilidade } \\
\hline $\mathrm{pH}$ & $\mathrm{P}$ & $\mathrm{K}^{+}$ & $\mathrm{Na}^{+}$ & $\mathrm{Ca}^{2+}$ & $\mathrm{Mg}^{2+}$ & $\mathrm{Al}^{3+}$ & $\mathrm{H}^{+}+\mathrm{Al}^{3+}$ & MO & $\mathrm{C} / \mathrm{N}$ \\
\hline \multicolumn{4}{|c|}{$--m g d^{-3}--$} & \multicolumn{4}{|c|}{---------------cmol $\mathrm{dm}_{\mathrm{c}}{ }^{-3}$--------------- } & \multicolumn{2}{|l|}{$\mathrm{g} \mathrm{kg}^{-1}$} \\
\hline 6,1 & 526 & 351 & 0,21 & 14,41 & 1,75 & 0,31 & 6,43 & 555,11 & $19 / 1$ \\
\hline \multicolumn{10}{|c|}{ Micronutrientes } \\
\hline \multicolumn{2}{|c|}{$\mathrm{B}$} & \multicolumn{2}{|c|}{$\mathrm{Fe}$} & \multicolumn{2}{|c|}{$\mathrm{Cu}$} & \multicolumn{2}{|c|}{$\mathrm{Mn}$} & \multicolumn{2}{|c|}{$\mathrm{Zn}$} \\
\hline \multicolumn{10}{|c|}{ 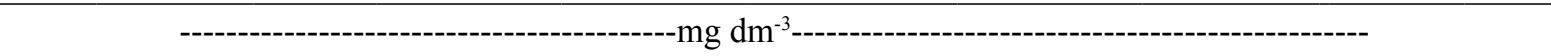 } \\
\hline \multicolumn{2}{|c|}{1,57} & \multicolumn{2}{|c|}{1,02} & \multicolumn{2}{|c|}{30,39} & \multicolumn{2}{|c|}{6,93} & \multicolumn{2}{|c|}{9,77} \\
\hline
\end{tabular}


potássica foram avaliadas pelo teste de Tukey a $5 \%$ de probabilidade e as referentes ao esterco por regressão polinomial, usando o programa estatístico SAS (SAS, 2010).

\section{RESULTADOS E DISCUSSÃO}

O fornecimento isolado de esterco bovino influenciou os teores foliares de todos os nutrientes avaliados, exceto $\mathrm{Ca}$ e $\mathrm{Mg}$, enquanto o fornecimento isolado de potássio influenciou apenas o teor de manganês. Ainda, quando aplicada em conjunto com esterco, a fonte de potássio foi prejudicial à absorção dos macronutrientes pelas plantas de noni, exceto para potássio (Tabela 3 ).

$\mathrm{O}$ incremento nas doses de esterco bovino promoveu aumento linear dos teores foliares de $\mathrm{N}$ nas plantas de noni, ao nível de $0,36 \mathrm{~g} \mathrm{~kg}^{-1}$ de $\mathrm{N}$ para cada aumento unitário do esterco de bovino fornecido (Figura 1). No tratamento com 11,6 kg planta-1 de esterco bovino as plantas estavam com $35 \mathrm{~g} \mathrm{~kg}^{-1}$, o que corresponde a um incremento de $14 \%$ nos teores de $\mathrm{N}$ em relação às plantas da testemunha, que continham $30,7 \mathrm{~g} \mathrm{~kg}^{-1}$ de $\mathrm{N}$. Esse incremento linear evidencia que as plantas responderam positivamente à aplicação de maiores doses de esterco bovino. Esta resposta é resultante do aumento da disponibilidade de nitrogênio no solo com o incremento das quantidades de esterco aplicadas, possibilitando maior suprimento desse nutriente às plantas. Um dos principais nutrientes disponibilizados no solo pelo esterco bovino é o nitrogênio e o esterco utilizado apresentava baixa relação $\mathrm{C} / \mathrm{N}$ (Tabela 2), indicando que o material seria mais facilmente decomposto e, consequentemente, incrementando o teor de nitrogênio no solo. Tendência semelhante foi apresentada por Araújo et al. (2007) em plantas de café em solo tratado com composto orgânico e biofertilizante bovino, ao registrarem incremento linear nos teores de nitrogênio na matéria seca foliar das plantas.

Os teores de $\mathrm{N}$ acumulados nas plantas de noni estão na faixa admitida como adequada para a cultura do café, que se situa entre 29 e 32 $\mathrm{g} \mathrm{kg}^{-1}$ (MALAVOLTA et al., 1997). Essa situação indica que a fertilização do noni com $90 \mathrm{~g}$ de ureia e esterco bovino a cada 120 dias foi suficiente para suprir a exigência da cultura em nitrogênio. Comparativamente, os resultados superam a amplitude de 19,24 a 23,16 $\mathrm{g} \mathrm{kg}^{-1}$ estabelecida como suficiente para a cultura do café por Clemente et al. (2008).

Assim como para o nitrogênio, os teores foliares de $\mathrm{P}$ das plantas de noni aumentaram linearmente com o incremento nas doses esterco, independentemente da adição de potássio (Figura 2). Verifica-se ainda que a cada aumento unitário na quantidade de esterco bovino fornecido ao solo as plantas apresentaram um incremento de $0,05 \mathrm{~g}$ $\mathrm{kg}^{-1}$ de $\mathrm{P}$ na matéria seca foliar; observa-se também

TABELA 3: Resumo das análises de variância, através do quadrado médio, referentes aos teores de nitrogênio $(\mathrm{N})$, fósforo $(\mathrm{P})$, potássio $(\mathrm{K})$, cálcio $(\mathrm{Ca})$, magnésio $(\mathrm{Mg})$, enxofre $(\mathrm{S})$, boro $(\mathrm{B})$, ferro $(\mathrm{Fe})$, manganês $(\mathrm{Mn})$ e zinco $(\mathrm{Zn})$ em plantas de noni tratadas com esterco bovino $(\mathrm{E}) \mathrm{e}$ potássio $(\mathrm{K})$.

TABLE 3: Summary of the analyzes of variance, through the mean square, referring to nitrogen (N), phosphorus $(\mathrm{P})$, potassium $(\mathrm{K})$, calcium $(\mathrm{Ca})$, magnesium $(\mathrm{Mg})$, sulfur $(\mathrm{S})$, boron $(\mathrm{B})$ iron $(\mathrm{Fe})$, manganese $(\mathrm{Mn})$ and zinc $(\mathrm{Zn})$ content in noni plants treated with cattle manure and potassium.

\begin{tabular}{|c|c|c|c|c|c|c|c|c|c|c|c|}
\hline \multirow{2}{*}{$\begin{array}{l}\text { Fonte de } \\
\text { variação }\end{array}$} & \multirow{2}{*}{ GL } & \multicolumn{10}{|c|}{ Quadrado Médio (QM) } \\
\hline & & $\mathrm{N}$ & $\mathrm{P}$ & $\mathrm{K}$ & $\mathrm{Ca}$ & $\mathrm{Mg}$ & $\mathrm{S}$ & $\mathrm{B}$ & $\mathrm{Fe}$ & $\mathrm{Mn}$ & $\mathrm{Zn}$ \\
\hline Bloco & 2 & $1,79^{\mathrm{ns}}$ & $0,37^{\mathrm{ns}}$ & $0,04^{\mathrm{ns}}$ & $0,50^{\mathrm{ns}}$ & $0,04^{\mathrm{ns}}$ & $0,16^{\mathrm{ns}}$ & $34,04^{\text {ns }}$ & $2725,0^{\text {ns }}$ & $50490,1^{*}$ & $30,5^{\mathrm{ns}}$ \\
\hline $\mathrm{K}$ & 1 & $3,37^{\mathrm{ns}}$ & $0,04^{\mathrm{ns}}$ & $2,04^{\mathrm{ns}}$ & $0,04^{\mathrm{ns}}$ & $0,37^{\mathrm{ns}}$ & $0,66^{\mathrm{ns}}$ & $48,16^{\text {ns }}$ & $198,3^{\text {ns }}$ & $278857,0 * *$ & $5,04^{\mathrm{ns}}$ \\
\hline $\mathrm{E}$ & 3 & $64,12 *$ & $0,81^{*}$ & $33,81^{* *}$ & $0,48^{\text {ns }}$ & $0,59^{\text {ns }}$ & $2,83 * *$ & $2783,4^{* *}$ & $23027,9^{* *}$ & $307385,5^{* *}$ & $477,3^{* *}$ \\
\hline $\mathrm{K} \times \mathrm{E}$ & 3 & $14,79^{\mathrm{ns}}$ & $0,59^{\mathrm{ns}}$ & $4,48 * *$ & $0,26^{\mathrm{ns}}$ & $0,15^{\mathrm{ns}}$ & $0,22^{\mathrm{ns}}$ & $1124,9 * *$ & $13501,4 * *$ & $148185,2 * *$ & $354,0 * *$ \\
\hline $\mathrm{R}$ & 14 & 63,08 & 0,18 & 0,56 & 0,3 & 0,23 & 0,4 & 52,13 & 742,6 & 11498,5 & 54,3 \\
\hline $\mathrm{cv}(\%)$ & & 6,49 & 16,36 & 6,81 & 7,62 & 18,96 & 7,14 & 9,65 & 7,69 & 6,37 & 6,63 \\
\hline
\end{tabular}

Em que: $n s=$ não significativo; * $e^{* *}$ respectivamente significativos para $p \leq 0,05$ e $p \leq 0,01$. GL $=$ grau de liberdade; $\mathrm{E}=$ esterco bovino; $\mathrm{R}=$ resíduo. 


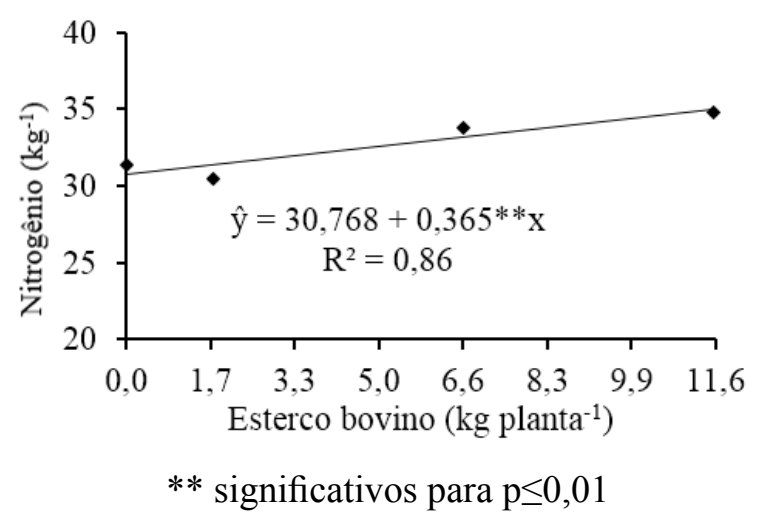

FIGURA 1: Teores de nitrogênio em folhas deplantas de noni sob adubação com esterco bovino.

FIGURE 1: Nitrogen contents in leaves of noni plants cultivated with cattle manure.

que, para o valor máximo de esterco fornecido $(11,6 \mathrm{~kg})$, as plantas apresentaram $2,76 \mathrm{~g} \mathrm{~kg}^{-1} \mathrm{de}$ P. Pelos dados, o incremento de esterco bovino contribuiu com um maior aporte de $\mathrm{P}$ ao solo se refletindo no incremento do nutriente na matéria seca foliar. Os resultados estão em conflito com os apresentados por Araújo et al. (2007) ao constatarem decréscimos lineares nos teores foliares de $\mathrm{P}$ em plantas de cafeeiro tratadas com doses de composto orgânico $(110,330,550,770$ e $990 \mathrm{~g} /$ vaso a 7 dm de solo), aos 204 dias após plantio.

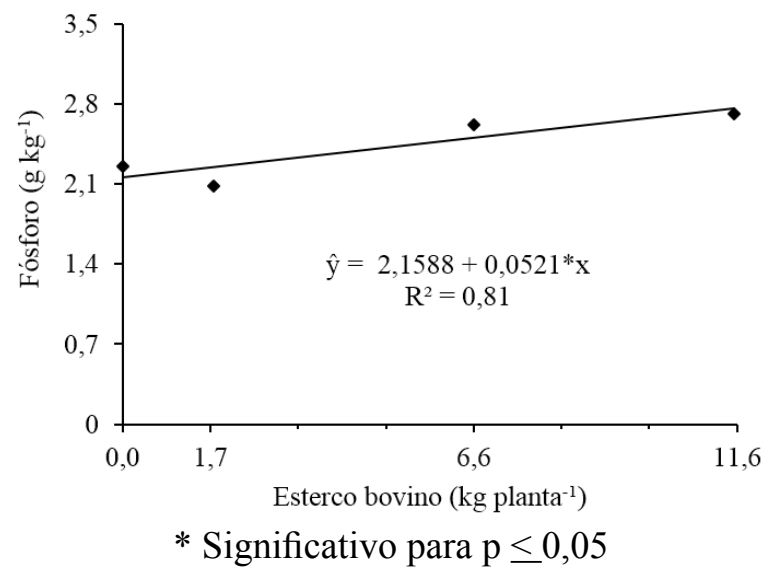

FIGURA 2: Teores de fósforo em folhas de plantas de noni sob adubação com esterco bovino.

FIGURE 2: Phosphorus contents in leaves of noni plants cultivated with cattle manure.

Comparativamente, os valores estão acima da faixa 1,6-1,9 $\mathrm{g} \mathrm{kg}^{-1}$ admitida como adequada para a cultura do café (MALAVOLTA et al., 1997). Isso indica que a matéria orgânica pode ter aumentado os teores de $\mathrm{P}$ disponível do solo e a adubação fosfatada ( $75 \mathrm{~kg} \mathrm{ha}^{1}$ ano), possivelmente, supriu a necessidade da cultura, tendo em vista que as plantas não emitiram sintomas visuais típicos de deficiência do respectivo nutriente.

A aplicação de esterco bovino e potássio ao solo elevou os teores foliares de $\mathrm{K}$ nas plantas de noni (Figura 3). No solo sem adição de $\mathrm{K}_{2} \mathrm{O}$, os teores do nutriente aumentaram até $13,6 \mathrm{~g} \mathrm{~kg}^{-1}$ referente à dose máxima estimada de $7,0 \mathrm{~kg}$ planta $^{-1}$ de esterco de bovino. Nos tratamentos com aplicação de $\mathrm{K}_{2} \mathrm{O}$, os teores de potássio aumentaram linearmente ao nível de 0,49 g para cada aumento unitário de esterco bovino aplicado ao solo atingindo o maior valor de $14,6 \mathrm{~g} \mathrm{~kg}^{-1}$ de $\mathrm{K}$.

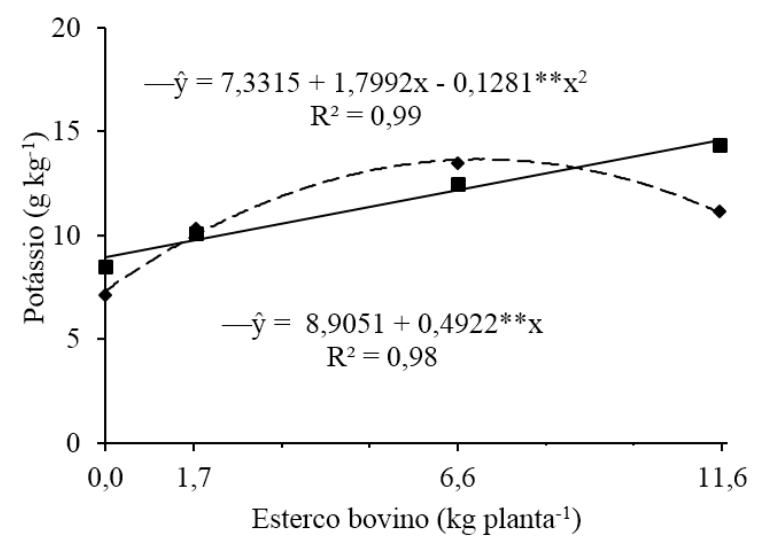

** significativos para $\mathrm{p} \leq 0,01$

FIGURA 3: Teores de potássio em folhas de plantas de noni sob adubação com esterco bovino em solo sem (---) e com (-) potássio.

FIGURE 3: Potassium contents in leaves of noni plants cultivated with cattle manure in soil without (---) and with (-) potassium.

Apesar dos valores de 13,6 e 14,6 $\mathrm{g} \mathrm{kg}^{-1}$ serem superiores aos $12 \mathrm{~g} \mathrm{~kg}^{-1}$ de $\mathrm{K}$ determinados por Singh e Rai (2007) na matéria seca foliar de plantas de noni nativas da Índia, comparativamente, os resultados estão abaixo da faixa de 22 a $25 \mathrm{~g}$ $\mathrm{kg}^{-1}$ expressa como recomendada para o cafeeiro (MALAVOLTA et al., 1997). Entretanto, essa situação pode ser resposta de uma menor exigência do Morinda citrifolia em potássio, em relação ao café. Outro aspecto, é que a fertilização a cada 120 
dias, após iniciado o experimento, com 210 g planta $^{-1}$ de $\mathrm{KCl}$, simultaneamente com os níveis de esterco bovino, supriu adequadamente as plantas, uma vez que as plantas não mostraram sintomas visuais característicos da deficiência desse macronutriente.

A acumulação foliar de cálcio e magnésio não foi significativamente influenciada pela interação esterco bovino $\mathrm{x}$ potássio e pelos efeitos isolados de nenhuma das fontes de variação (Tabela 4). Os teores foliares de cálcio variaram de 7,3 a $8,0 \mathrm{~g} \mathrm{~kg}^{-1}$ nas plantas cultivadas em solo sem e com adição de $\mathrm{K}$. Os teores de magnésio variaram de 2,3 a $3,0 \mathrm{~g} \mathrm{~kg}^{-1}$ nas plantas cultivadas em solo sem fornecimento de $\mathrm{K}$ e de 2,0 a 3,0 nas cultivadas em solo com K. Os teores médios foram de 7,62 e $2,54 \mathrm{~g} \mathrm{~kg}^{-1}$ para cálcio e magnésio, respectivamente (Tabela 4). Comparando com o cafeeiro, as plantas de noni não estavam adequadamente supridas nos respectivos macronutrientes, pois, de acordo com Malavolta et al. (1997), teores adequados de cálcio para essa cultura devem estar entre 13 e $15 \mathrm{~g} \mathrm{~kg}^{-1} \mathrm{e}$ de magnésio entre 4,0 e 4,5 $\mathrm{g} \mathrm{kg}^{-1}$.

Quanto ao enxofre, apesar dos teores foliares terem sido influenciados significativamente pelas doses de esterco bovino, não se ajustaram a nenhum modelo de regressão, por isso, foram representados pelo valor médio $8,9 \mathrm{~g} \mathrm{~kg}^{-1}$ de enxofre (Figura 4). Esse valor é considerado excessivamente alto para culturas da família do noni, como o cafeeiro, e para a grande maioria das plantas exploradas comercialmente no Brasil. Considerando que mesmo nos tratamentos onde não foi fornecido esterco bovino as plantas apresentaram teores de enxofre elevados e que não apresentaram sintomas de toxicidade pelo nutriente, infere-se que a cultura evidencia ser exigente em enxofre. Araújo et al. (2007) verificaram decréscimo nos teores de enxofre da matéria seca foliar de plantas de noni submetidas a doses crescentes de composto orgânico, aos 204 dias após plantio. Ao considerar que o solo antes do experimento (Tabela 1) apresentava baixos teores de matéria orgânica, as plantas absorveram o enxofre oriundo do esterco de bovino e do superfosfato simples aplicado ao solo.

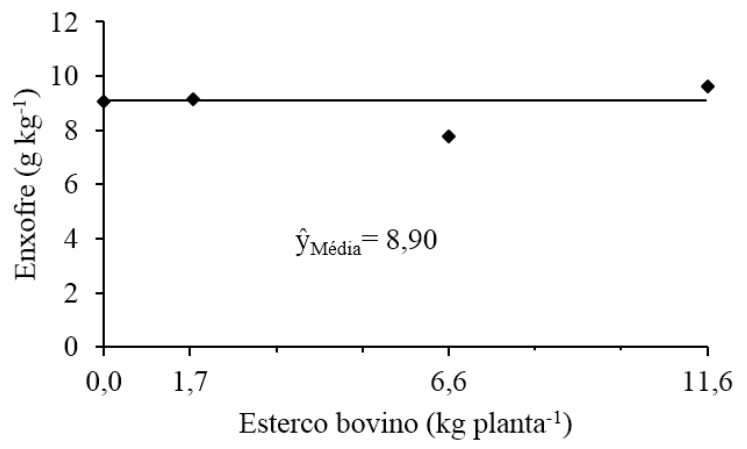

Teores de enxofre em folhas de plantas FIGURA 4: de noni sob adubação com esterco bovino.

Sulfur contents in leaves of noni plants FIGURE 4: cultivated with cattle manure.

Exceto no tratamento com potássio, no solo

TABELA 4: Teores de cálcio e magnésio em folhas de noni sob adubação com de esterco bovino em solo sem e com potássio.

TABLE 4: Calcium and magnesium contents in leaves of noni plants under fertilization with cattle manure in soil without and with potassium.

\begin{tabular}{|c|c|c|c|c|}
\hline \multirow{2}{*}{$\begin{array}{c}\text { Esterco } \\
\left(\mathrm{kg} \text { planta }^{-1}\right)\end{array}$} & \multicolumn{2}{|c|}{ Cálcio $\left(\mathrm{g} \mathrm{kg}^{-1}\right)$} & \multicolumn{2}{|c|}{ Magnésio $\left(\mathrm{g} \mathrm{kg}^{-1}\right)$} \\
\hline & Sem K & Com K & Sem K & Com K \\
\hline 0,0 & $8,0 \mathrm{Aa}$ & $8,0 \mathrm{Aa}$ & $3,0 \mathrm{Aa}$ & $3,0 \mathrm{Aa}$ \\
\hline 1,7 & 7,3 Aa & 7,3 Aa & $2,7 \mathrm{Aa}$ & $2,0 \mathrm{Aa}$ \\
\hline 6,6 & $8,0 \mathrm{Aa}$ & 7,3 Aa & 2,3 Aa & $2,3 \mathrm{Aa}$ \\
\hline 11,6 & 7,3 Aa & 7,7 Aa & $2,7 \mathrm{Aa}$ & 2,3 Aa \\
\hline dms Linha & \multicolumn{2}{|c|}{0,97} & \multicolumn{2}{|c|}{0,84} \\
\hline dms Coluna & \multicolumn{2}{|c|}{1,32} & \multicolumn{2}{|c|}{1,14} \\
\hline Média geral & \multicolumn{2}{|c|}{7,62} & \multicolumn{2}{|c|}{2,54} \\
\hline $\mathrm{CV}(\%)$ & \multicolumn{2}{|c|}{7,30} & \multicolumn{2}{|c|}{18,96} \\
\hline
\end{tabular}

Médias seguidas pela mesma letra minúscula nas colunas e maiúscula na linha não diferem estatisticamente entre si pelo teste Tukey a $5 \%$ de probabilidade 
com maior nível de esterco bovino, os teores de boro acumulados nas folhas de noni foram inibidos com o aumento dos níveis de esterco bovino fornecido, independentemente da adição de potássio ou não ao solo (Figura 5). O declínio de boro na matéria seca foliar das plantas, em função do aumento de esterco bovino no solo, segundo Goldberg (1997) e Novais et al. (2007), é mais frequentemente registrado em algumas das situações: a) a matéria orgânica do solo adsorve mais fortemente o boro do que os constituintes minerais resultando também na diminuição da sua disponibilidade às plantas; b) a competição entre boro e nitrogênio pode limitar a disponibilidade de boro no solo e comprometer o suprimento adequado às plantas (MARSCHNER, 2005).

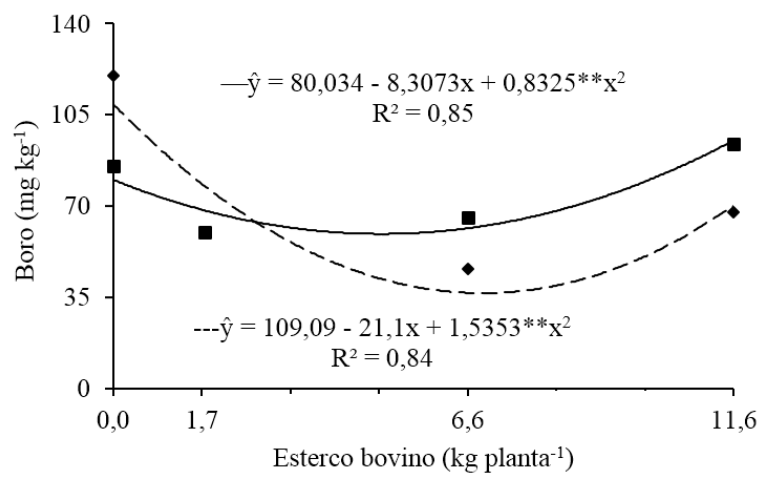

** Significativos para $\mathrm{p} \leq 0,01$

FIGURA 5: Teores de boro em folhas de plantas de noni sob adubação com esterco bovino em solo sem (---) e com (-) potássio.

FIGURE 5: Boron contents in leaves of noni plants cultivated with cattle manure in soil without (---) and with (-) potassium.

Por outro lado, nos tratamentos com $\mathrm{K}_{2} \mathrm{O}$, principalmente para as maiores doses de esterco, os teores de boro foram superiores. De acordo com Davis et al. (2003), o potássio exerce relação sinérgica com o boro, ou seja, a maior disponibilidade de potássio no solo em função da aplicação de $\mathrm{KCl}$ eleva a disponibilidade no solo da acumulação foliar do micronutriente às plantas. Os menores valores de 36,6 e $59,3 \mathrm{mg} \mathrm{kg}^{-1}$ de boro nas folhas de noni, foram obtidos nas doses mínimas estimadas de 6,9 e $5,0 \mathrm{~kg}$ de esterco bovino no solo sem e com potássio, respectivamente. Esses dados estão próximos ou superam os $37,53 \mathrm{e}$ $48,93 \mathrm{mg} \mathrm{kg}^{-1}$ em mudas de cafeeiros obtidos por Gonçalves (2005) e estão na faixa de 40 e 100 mg $\mathrm{kg}^{-1}$ estabelecida como adequada por Malavolta et al. (1997) para café.

Os teores foliares de ferro responderam significativamente aos efeitos da interação esterco bovino x potássio no solo. Nos tratamentos com potássio os valores aumentaram linearmente, ao nível de $19,8 \mathrm{mg} \mathrm{kg}^{-1}$ por incremento unitário do esterco bovino fornecido, atingindo o valor máximo de $488,8 \mathrm{mg} \mathrm{kg}^{-1}$ no tratamento com a maior dose do insumo orgânico $\left(11,6 \mathrm{~kg}\right.$ planta $\left.^{-1}\right)$. Nas plantas desenvolvidas no solo sem potássio os teores de ferro não se ajustaram a nenhum tipo de regressão, sendo representados pela média de $351,6 \mathrm{mg} \mathrm{kg}^{-1}$ (Figura 6). Verifica-se, assim como para o boro, que os teores de ferro foram superiores nas plantas dos tratamentos com potássio, principalmente nas maiores doses de esterco bovino. A adição de potássio ao solo resultou em maior acúmulo de biomassa foliar contribuindo para o aumento da absorção e acumulação do micronutriente pelas plantas.

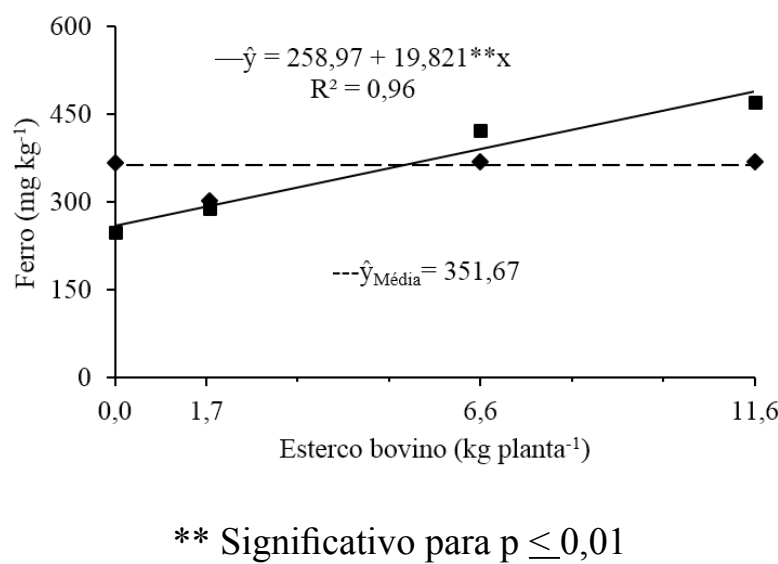

FIGURA 6: Teores de ferro em folhas de plantas de noni sob adubação com esterco bovino em solo sem (---) e com (-) potássio.

FIGURE 6: Iron contents in leaves of noni plants cultivated with cattle manure in soil without (---) and with (-) potassium.

Os teores de ferro de 351,6 e 488,8 $\mathrm{mg} \mathrm{kg}^{-1}$ nas plantas cultivadas no solo sem e com potássio, respectivamente, são superiores à amplitude de 94,12 a $115,33 \mathrm{mg} \mathrm{kg}^{-1}$ adotada como suficiente às plantas do cafeeiro (GONÇALVES, 2005). Ao se considerar que as exigências do noni por ferro sejam semelhantes aos do cafeeiro, a variação 351,6 e 488,8 $\mathrm{mg} \mathrm{kg}^{-1}$ foi superior à adotada como adequada para a cultura que varia de 100 a 130 mg kg-1 (MALAVOLTA et al., 1997), e expressa que as plantas na época da amostragem estavam 
suficientemente supridas em ferro. Os elevados valores de ferro na matéria seca foliar das plantas são respostas dos elevados teores de ferro no solo com $38,14 \mathrm{mg} \mathrm{kg}^{-1}$ (Tabela 1) e no esterco de bovino aplicado com $30,39 \mathrm{mg} \mathrm{kg}^{-1}$ do micronutriente (Tabela 2).

Os teores de manganês, assim como os de ferro, também foram influenciados pela interação esterco bovino x potássio (Figura 7). Nas plantas dos tratamentos sem potássio, os teores de manganês não se adequaram a nenhum modelo matemático, sendo a variação representada pela média de 1576 $\mathrm{mg} \mathrm{kg}{ }^{-1}$. Na matéria seca das plantas dos tratamentos com potássio, a acumulação foi estimulada com o aumento do fornecimento de esterco bovino, atingindo o maior valor máximo de $2328,6 \mathrm{mg} \mathrm{kg}$ 1, no nível máximo da matéria orgânica aplicada, $11,6 \mathrm{~kg}$ planta $^{-1}$. Esses valores são expressivamente superiores à variação de 225,14 a 253,60 $\mathrm{mg} \mathrm{kg}^{-1}$ de Mn apresentada por Gonçalves (2005) em mudas de cafeeiro e a amplitude de $80-100 \mathrm{mg} \mathrm{kg}^{-1}$ admitida como suficiente ao cafeeiro por Malavolta et al. (1997).

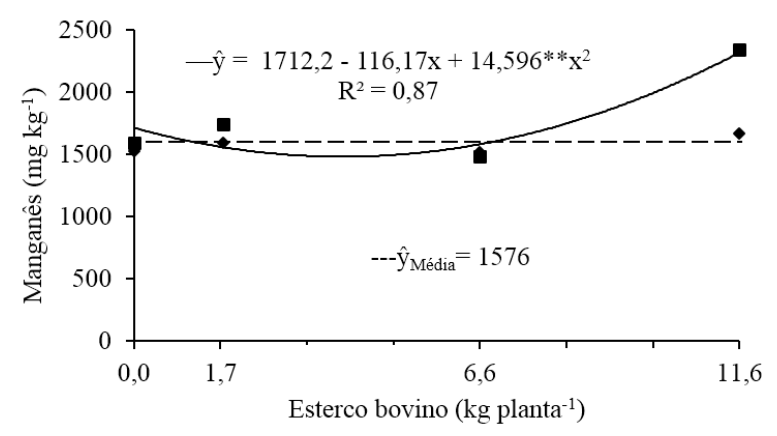

** Significativo para $\mathrm{p} \leq 0,01$

FIGURA 7: Teores de manganês em folhas de plantas de noni sob adubação com esterco bovino em solo sem (---) e com (一) potássio.

FIGURE 7: Manganese in leaves of noni plants cultivated with cattle manure in soil without (---) and with (-) potassium.

Nas plantas dos tratamentos sem potássio, os teores foliares de zinco aumentaram linearmente, ao nível de $0,49 \mathrm{mg} \mathrm{kg}^{-1}$ por aumento unitário das doses de esterco bovino, atingindo o maior valor de $111,7 \mathrm{mg} \mathrm{kg}^{-1}$ referente à dose $11,6 \mathrm{~kg}_{\text {planta }}{ }^{-1}$ de esterco bovino (Figura 8). Nas plantas dos tratamentos com potássio, a acumulação foliar de $\mathrm{Zn}$ inicialmente diminuiu com o aumento da aplicação de esterco bovino até o menor valor de $99 \mathrm{mg} \mathrm{kg}^{-1} \mathrm{de}$
Zn no nível mínimo estimado de 5,21 $\mathrm{kg}_{\text {planta }}{ }^{-1} \mathrm{de}$ esterco bovino. Ao contrário do registrado para $\mathrm{B}$, $\mathrm{Fe}$ e $\mathrm{Mn}$, os teores de $\mathrm{Zn}$ foram predominantemente superiores nas plantas do solo sem potássio. Esse comportamento, conforme Dechen e Natchtigall, (2006), é resposta da ação antagônica do potássio com o zinco, visto que os teores de Fe e Mn foram superiores nos tratamentos com potássio.

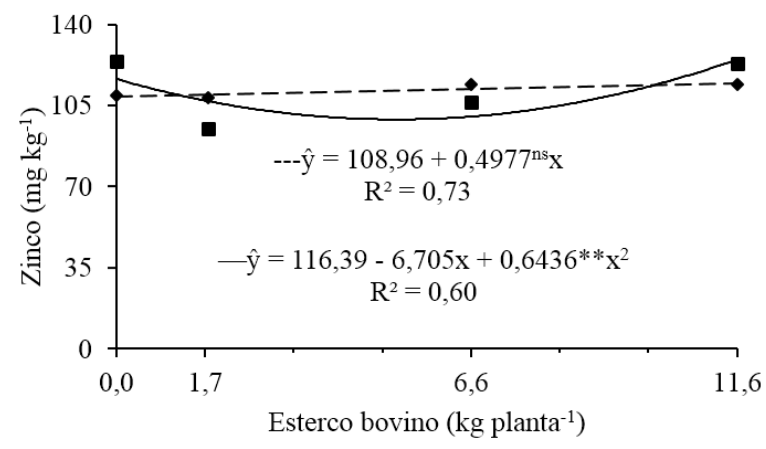

ns $=$ não significativo $; * *$ significativo para $\mathrm{p} \leq 0,01$ FIGURA 8: Teores de zinco em folhas de plantas de noni sob adubação com esterco bovino em solo sem (---) e com (-) potássio.

FIGURE 8: Zinc contents in leaves of noni plants cultivated with cattle manure in soil without (---) and with (-) potassium.

Os resultados são expressivamente superiores à faixa de 12,08 a 15,54 $\mathrm{mg} \mathrm{kg}^{-1}$ obtida por Gonçalves (2005) em plantas de cafeeiro e à faixa admitida como adequada ao cafeeiro de 15 a $20 \mathrm{mg} \mathrm{kg}^{-1}$ por Malavolta et al. (1997). No entanto, as plantas não apresentaram sintomas de toxidez e evidênciando que, além do Mn, o noni também absorve quantidades elevadas de $\mathrm{Zn}$ em comparação ao café.

\section{CONCLUSÕES}

A cultura de noni (Morinda citrifolia L.) respondeu significativamente à aplicação de esterco bovino e potássio, o que ficou evidenciado pelos maiores teores foliares para quase todos os nutrientes, exceto $\mathrm{Ca}$ e $\mathrm{Mg}$.

A acumulação foliar de ferro, manganês e zinco pelo noni é superior ao cafeeiro.

Os aumentos lineares nas concentrações foliares da maioria dos nutrientes indicam a conveniência de novos estudos com maiores doses de aplicação de esterco bovino, potássio e outros nutrientes, objetivando conhecer as máximas doses 
de aplicação que podem resultar em incremento de teores foliares.

O estabelecimento de faixas de interpretação de teores de nutrientes adequados para noni faz-se necessário para auxiliar as discussões de futuros estudos de adubação e nutrição da cultura.

\section{REFERÊNCIAS BIBLIOGRÁFICAS}

ARAÚJO, J. B. S. et al. Composto orgânico e biofertilizante na nutrição do cafeeiro em formação no sistema orgânico: teores foliares. Coffee Science, Lavras, v. 2, n. 1, p. 20-28, jan./jun. 2007.

BASAR, S. et al. Analgesic and antiinflamatory activity of Morinda citrifolia L. (noni) fruit. Phytother Res. Institute of Experimental and Clinical Pharmacology and Toxicology, University Clinic Hamburg, v.24, n.1, p. 38-42, Jan, 2010. BERNARDO, S.; SOARES, A. A.; MANTOVANI, E. C. Manual de irrigação. 2. ed.Viçosa: UFV, 2006.

CLEMENTE, F. M. V. T. et al. Faixas críticas de teores foliares de macronutrientes no cafeeiro em pós-plantio - primeiro ano. Coffee Science, Lavras, v. 3, n. 1, p. 47-57, jan./jun. 2008.

DAVIS, J. M. et al. Boron improves growth, yield, quality and nutrient content of tomato. Journal American Society Horticulture Science. v. 128, n. 3 p. 441-446, 2003.

DECHEN, A. R.; NACHTIGAL, G. R. Micronutrientes In.: FERNANDES, M. S. Nutrição mineral de plantas. Viçosa, Sociedade Brasileira de Ciência do Solo, 2006. p. 327-354.

EMBRAPA. Centro Nacional de Pesquisa de Solos. Manual de métodos de análise do solo. 3 . ed. Rio de Janeiro, 2011, 230 p. (Embrapa - CNPS. Documentos, 132).
GOLDBERG, S. Reactions of boron with soils. Plant and Soil, Dordrecht, v. 193, p. 35-48, 1997. GONÇALVES, M. S. Faixas críticas de teores foliares de nutrientes em mudas de cafeeiro (Coffea arabica L.) produzidas em tubetes. 2005. Dissertação (Mestrado em Fitotecnia) Universidade Federal de Lavras, Lavras, 2005.

MACPHERSON, H. et al.. The Potential for a New Value Adding Industries for Noni Tropical Fruit Producers. Rural Industries Research and Developmenmt Corporation. Australian Government: Sidney, 2007. 132 p.

MALAVOLTA, E.; VITTI, G. C.; OLIVEIRA, S. A. Avaliação do estado nutricional das plantas: princípios e aplicações. Piracicaba: POTAFOS, 1997. $201 \mathrm{p}$.

MARSCHNER, H. Mineral nutrition of higher plant. 2nd ed. New York: Academy, 2005, 889 p.

MENDES, J. J.S. et al. 2011. Macro e micronutrientes no solo, folhas e frutos de noni (Morinda citrifolia) em são luís - MA. Revista Verde, Mossoró, v. 6, n. 5, p. 123 - 133 dez. 2011(EDIÇÃO ESPECIAL) NELSON, S. C. Noni Seed Handling and Seedling Production. Cooperative Extension Service. College of Tropical Agriculture and Human Resources. University of Hawaii at Manoa, 2005.

NOVAIS, R. F. et al. Fertilidade do solo. Sociedade brasileira de Ciência do Solo: Viçosa, 2007.

NUGEO/LABMET. Atlas do Maranhão. São Luís: UEMA, 2002.

SAS Institute Inc. SAS/STAT 9.22 User's Guide. Cary, NC: SAS Institute Inc. 2010. 8460 p.

SINGH, D. R.; RAI, R. B. Morinda citrifolia linn. ó an important fruit tree of andaman and nicobar islands. Journal Indian of Natural Product Radiance. New Delhi, v. 6, n. 1. p. 62-65, 2007. 